\title{
Diagnostic accuracy of toluidine blue in early detection of oral squamous cell carcinoma
}

\author{
M uhammad Salman Chishty ${ }^{1}$, M alik Ali H assan Sajid ${ }^{2}$, Shoaib Younus ${ }^{3}$, U sman ul H aq ${ }^{4}$ \\ ${ }^{1}$ Assistant Professor, Department of O ral and M axillofacial Surgery, Institute of Dentistry, CM H Lahore M edical College and Institute of \\ D entistry, L ahore, Pakistan, ${ }^{2}$ Associate Professor, Department of O ral and M axillofacial Surgery, FMH College of M edicine and Dentistry, \\ Lahore, Pakistan ${ }^{3}$ Associate Professor, D epartment of O ral and Maxillofacial Surgery, Institute of D entistry, CM H Lahore M edical College, \\ Lahore, Pakistan, ${ }^{4}$ Assistant Professor, H ead of Department of Oral and Maxillofacial Surgery, HIT EC-IMS Dental College, T axila Cantt, \\ Pakistan. \\ Correspondence to: D r. M alik Ali H assan Sajid, E mail: draliz14@yahoo.com
}

\begin{abstract}
Background: Indian sub-continent (India, Pakistan, and Bangladesh) is one of the high-risk populations for oral cancer cases. Intraoral screening is critical to diagnosis and treating oral cancer at an early stage for a better prognosis. Among the diagnostic adjuncts, toluidine blue staining is considered a simplistic, cost-effective, and highly sensitive method. T he objective of the current study was to find out the diagnostic accuracy of toluidine blue in the early detection of oral squamous cell carcinoma.

Patients and methods: This prospective observational study was undertaken at the Department of 0 ral and M axillofacial Surgery, Institute of Dentistry, CM H Lahore M edical College from15-09-2019 to 15-03-2020 after getting approval from IRB. Based on inclusion criteria, a sample size of 100 was calculated and enrolled in the study. $\mathrm{N}$ on-probability convenient sampling technique was utilized. O ral staining of 100 patients was done with $1 \%$ toluidine blue on an OPD basis, and incisional biopsies were then performed. Staining pattern and histopathology reports of patients were evaluated to assess the diagnostic accuracy

Results: T he study results revealed the sensitivity of T oluidine Blue as $89.87 \%$, and specificity of toluidine blue was found as $76.19 \%$. Positive and negative predictive values of Toluidine Blue remained $93.42 \%$ and $66.67 \%$, respectively.

Conclusion: T oluidine blue has good diagnostic accuracy for early detection of oral squamous cell carcinoma (SCC). Keywords:

Oral Squamous cell carcinoma, Pre-malignant lesion, D iagnostic accuracy, T oluidine blue.
\end{abstract}

\section{INTRODUCTION}

Indian sub-continent (India, Pakistan, and Bangladesh) is one of the high-risk populations for oral cancer cases and a leading cause of mortality, accounting for nearly one-third of all cancers. ${ }^{1,2}$

Oral squamous cell carcinoma (OSCC) is the commonest type accounting for $90-95 \%$ of all oral cancer cases. ${ }^{3,4}$ Clinically, OSC C may present as a persistent ulcer, leukoplakia, erythroplakia, a lump, or a nodule. ${ }^{5} \mathrm{~T}$ he most commonly involved sites include the tongue, lip, cheek mucosa, and floor of the mouth. ${ }^{6,7}$ Oral cancer prognosis is directly linked with the stage of the tumor at diagnosis. ${ }^{8-10} \mathrm{O}$ ral $\mathrm{C}$ ancer detection at an earlier stage is of utmost significance as survival rate significantly improves for early-stage OSCC. ${ }^{11-13}$ Periodic intraoral screening is critical to early diagnosis. ${ }^{14,15}$ In-vivo staining is considered as one of the simplistic, cost-effective, and highly sensitive

C onflict of interest: The authors declared no conflict of interest exists.

Citation: Chishty M S, Sajid M AH, Y ounus S, H aq U. Diagnostic accuracy of toluidine blue in early detection of oral squamous cell carcinoma. J Fatima Jinnah M ed U niv. 2021; 15(2): 91-94. diagnostic adjuncts. ${ }^{16}$ T he utility of toluidine blue has been reported for staining of potential malignant and pre-malignant lesions. ${ }^{10}$ The sensitivity of toluidine blue used in-vivo for squamous cell carcinoma to stain positive has been shown somewhat $93.5 \%$ to $97.8 \%$, and that of specificity was reported from $73.3 \%$ to $92.9 \%{ }^{10}$ Another study reported sensitivity of $79.5 \%$ and specificity around $62 \%$ with pre-cancerous lesions. ${ }^{2}$ Moreover, sensitivity and specificity of toluidine blue has been reported more than $90 \%$ used in vivo for premalignant and malignant lesions for OSC C. ${ }^{17,18}$ Authors of a study demonstrated reduction of the false positive rate by $55.26 \%$ while maintained a $100 \%$ negative predictive value (NPV) and suggested more clinical trials in different populations. ${ }^{10}$

The study aimed to determine the diagnostic accuracy of toluidine blue staining to detect premalignant lesion with high suspicion of OSCC, thus the results of the study may be exploited to guide the clinicians for early detection of the potential malignant oral cavity lesions by utilizing a simple, non-invasive technique with good diagnostic accuracy. 


\section{PATIENTS AND METHODS}

This prospective observational study was undertaken at the Department of Oral \& Maxillofacial Surgery, Institute of Dentistry, CMH Lahore M edical College from15-09-2019 to 15-03-2020 after approval from Institutional Review Board.

An online sample size calculator (O penE pi) was utilized to calculate the sample size of 100 . D ata were collected by using the non-probability sampling technique. Patients' age ranged from 24-65 as this is the most susceptible age group for potential squamous cell carcinoma due to habits, having non-healing ulcers, and with high risk or suspicion of malignancy (with history of betel nuts, Paan chewing, smoking, snuff dipping, and alcohol) diagnosed by taking a thorough history and clinical examination (so patients with non-healing oral ulcers for more than one month and habits were labeled as high-risk patients) and were included in the study). Patients who had clinically evident and histopathologically proven carcinoma or had lesions without risk or suspicion of malignancy were excluded. Informed consent was taken from the patients. A predesigned Performa was used for data collection.

Oral lesions of included patients were swabbed with $1 \%$ flavored acetic acid solution for one minute to remove any debris from the lesion. T hen a pre-soaked swab was used to apply the $1 \%$ toluidine blue prepared by the pharmacy for one minute. Finally, 1\% acetic acid was utilized to remove any excessive toluidine. The staining pattern was recorded either as negative or positive. Lesions that retained toluidine blue after applying $1 \%$ acetic acid were considered positive, while lesions that could not retain toluidine blue dye when $1 \%$ acetic acid was applied were considered negative. Incisional biopsy of the lesion was taken under $L A$ and sent to the histopathology laboratory of the H ospital. $T$ his whole procedure was performed on a dental chair on an OPD basis by the principal investigators. All the data, including the staining pattern and result of the biopsy report were recorded.

Data analysis was performed by utilizing SPSS version 25.0. Frequencies and percentages were used to describe the qualitative variables like gender. Q uantitative variables like age were described in the form of mean +1 - Standard Deviation (SD). A contingency table of $2 \times 2$ was formulized for positive predictive value, negative predictive value, sensitivity, specificity, and accuracy of toluidine blue staining to detect oral malignant lesions while taking histopathology as a gold standard.
Table 1. Distribution of site of lesion in relation to the gender of patients.

\begin{tabular}{|c|c|c|c|}
\hline \multirow[b]{2}{*}{ Site of lesion } & \multicolumn{2}{|c|}{ G ender } & \multirow[b]{2}{*}{$\begin{array}{l}\text { T otal } \\
n(\%)\end{array}$} \\
\hline & $\begin{array}{l}\text { M ale } \\
n(\%)\end{array}$ & $\begin{array}{c}\text { Female } \\
n(\%)\end{array}$ & \\
\hline Alveolus & $7(12.3)$ & $1(2.3)$ & $8(8)$ \\
\hline Buccal mucosa & $22(22)$ & $16(37.2)$ & $38(38)$ \\
\hline Lip & $6(10.5)$ & $5(11.6)$ & $11(11)$ \\
\hline T ongue & $22(38.6)$ & $21(48.8)$ & $43(43)$ \\
\hline T otal & 57 & 43 & 100 \\
\hline
\end{tabular}

Table 2. D iagnostic accuracy of toluidine blue in the detection of oral malignancies.

\begin{tabular}{|c|c|c|c|}
\hline \multirow[b]{2}{*}{ D iagnostic accuracy } & \multicolumn{2}{|c|}{ Biopsy } & \multirow[b]{2}{*}{$\begin{array}{l}\text { Total } \\
n(\%)\end{array}$} \\
\hline & $\begin{array}{c}\text { M alignant } \\
n(\%)\end{array}$ & $\begin{array}{c}\text { Benign } \\
n(\%)\end{array}$ & \\
\hline Positive & $71(89.8)^{\top P}$ & $5(23.8)^{\mathrm{FP}}$ & $76(76)$ \\
\hline N egative & $8(10.1)^{\mathrm{FN}}$ & $16(76.2)^{\top \mathrm{N}}$ & $24(24)$ \\
\hline T otal & 79 & 21 & 100 \\
\hline Sensitivity & \multicolumn{3}{|c|}{$89.9 \%(81.02 \%$ to $95.53 \%)$} \\
\hline Specificity & \multicolumn{3}{|c|}{$76.2 \%(52.83 \%$ to $91.78 \%)$} \\
\hline Positive predictive value & \multicolumn{3}{|c|}{$93.4 \%(86.81 \%$ to $96.84 \%)$} \\
\hline $\mathrm{N}$ egative predictive value & \multicolumn{3}{|c|}{$66.7 \%(49.85 \%$ to $80.10 \%)$} \\
\hline D iagnostic accuracy & \multicolumn{3}{|c|}{$87.0 \%(78.80 \%$ to $92.89 \%)$} \\
\hline
\end{tabular}

\section{RESULTS}

A total of 100 patients were enrolled in the study with slight male predominance; $57(57 \%)$ males and 43 $(43 \%)$ female patients (male to female ratio being 1.32:1). M ean age was44.01+12.8 years (range, 24 to 65 years). $T$ he mean ages of male and female patients were $44.42 \pm 12.92$ and $43.46 \pm 12.76$ years, respectively. Concerning the site of a highly suspicious lesion, $8(8 \%)$ patients had lesions involving alveolus, 38 (38\%) patients had lesions in Buccal Mucosa, 11 (11\%) patients had lesions on their lips, and $43(43 \%)$ patients had lesions on the tongue ( $T$ ablel).

The sensitivity of toluidine blue was noted at $89.87 \%$, i.e., it accurately detected 71 patients who had malignant lesions. T he specificity of toluidine blue was $76.19 \%$, i.e., it accurately detected 16 patients who did not have malignant lesions. T he positive predictive and negative predictive value of toluidine blue was $93.42 \%$ and $66.67 \%$, respectively ( $T$ able2).

\section{DISCUSSION}

Oral squamous cell carcinoma cases are on the rise is in Southeast Asian region. ${ }^{1}$ Those with habits of using different forms of tobacco, smoking, drinking and betel nut chewing have a higher risk of having oral cancer.1Screening for early diagnosis of oral malignant lesions is of utmost importance in this part of the world. T oluidine blue can be utilized as a diagnostic adjunct to detect oral malignant and pre-malignant lesions. Its higher efficacy has been reported with encouraging results. ${ }^{10} 0$ nofre and colleagues reported the sensitivity of $100 \%$ to detect the carcinoma-in-situ and invasive 
carcinoma, and there were no false-negative results noted. They also observed false-negative results as the dysplastic lesions did not retain toluidine blue stain while false positivity rate remained for lesions with no dysplasia or showing atypical cells. The toluidine blue specificity was noted around $65 \% .{ }^{19}$

In a study by $\mathrm{H}$ egde and coworkers, the sensitivity and specificity were $97.29 \%$ and $62.5 \%$, respectively, for lesions as non-healing ulcers with suspicion of malignancies. In comparison, they reported falsepositivity and false-negativity as $7.69 \%$ and $16.67 \%$, respectively. $T$ hey proposed that the specificity in their study was reduced because it was retained in some of the benign lesions. ${ }^{20}$ As far as the current study is concerned, it also had false positives, and some benign lesions also retained stain may be due to inflammation in the area. Gupta and coauthors noticed a sensitivity of toluidine blue as $96.9 \%$ and specificity of $86 \%$ in the detection of oral malignant lesions. They also noted $64 \%$ sensitivity and $86 \%$ specificity for pre-malignant lesions. $^{21}$ In the current study, the sensitivity of T oluidine Blue remained $89.87 \%$ which is closer to those of $\mathrm{H}$ egde and associates, and Gupta and colleagues reported sensitivities of toluidine blue. ${ }^{20,21}$

False-positive has been described with the variable frequency with regard to retention of T oluidine Blue for non-dysplastic lesions. Epstein and coauthors reported toluidine blue sensitivity as $92.5 \%$ and specificity as $63.2 \%$, which are in accordance with the results of the current study where we reported the specificity around $76 \% .{ }^{10}$ In current study enrolled patients with oral lesion and with high suspicion or risk of malignancy (with history of betel nuts, Paan chewing, smoking, snuff dipping and alcohol) diagnosed by thorough history and examination whereas done by Epstein and coworkers who included 84 patients with 97 suspicious lesions. ${ }^{10} \mathrm{~T}$ his study shows that oral premalignant lesions are almost equally common in both genders in the suspected high-risk population in our setting. As far as the lesion site is concerned, malignancies were most common on the tongue's lateral border, followed by buccal mucosa and lower lip, while alveolus and palate were at the bottom. In the study by $\mathrm{H}$ odge and coauthors, $2 / 3^{\text {rd }}$ of patients $(n=38)$ presented with a history of betel quid chewing, and 52 patients presented a history of cigarette smoking. The sites of involvement of suspected lesions were noted as; on the buccal mucosa $(n=25)$, tongue ( $n=16)$, gingivae $(n=9)$, lip $(n=3)$, palate $(n=2)$, the floor of the mouth $(n=2)$, and retromolar region $(n=1) .{ }^{20} \mathrm{In}$ their study buccal mucosa was involved more than other sites which seems comparable to the current study.

In the current study, toluidine blue's sensitivity was $89.87 \%$, which accurately detected 71 patients with a malignant lesion. Specificity of T oluidine Blue was noted $76.19 \%$ that means it accurately detected 16 patients who did not have malignant lesions. These results are well in line with the figures described in earlier studies. ${ }^{10,21}$ Current study, reported $23.8 \%$ falsepositive and $10.1 \%$ as false-negative whereas $\mathrm{H}$ egde and coauthors reported false-positivity and false negativity of $7.69 \%$ and $16.67 \%$ respectively. ${ }^{20}$ Gupta and colleagues reported false-positive rate of $14 \% . .^{21}$

In the current study, positive and negative predictive values of toluidine blue have been reported as $93.42 \%$ and $66.67 \%$, respectively, while a previous study described $100 \%$ negative predictive value. ${ }^{10}$

The use of toluidine blue has previously been reported in various studies as a valuable adjunct to the clinical judgment which can assist in choosing the site of the biopsy; a valuable adjunct in the diagnostic process, and it can preferably be used as a prime aid in early detection of oral pre-malignant and malignant lesions. ${ }^{22-25}$

\section{CONCLUSIONS}

Toluidine blue is one of the diagnostic adjuncts available that can be utilized for the early detection of oral squamous cell carcinoma. The method is simple, non-invasive, and can be used as a chair-side technique with good diagnostic accuracy.

\section{REFERENCES}

1. Siddiqui IA, Farooq MU, Siddiqui RA, Rafi SM. Role of toluidine blue in early detection of oral cancer. Pak J M ed Sci. 2006; 22:184-7.

2. Mummudi N, Agarwal JP, Chatterjee S, M allick I, G hoshLaskar S. Oral cavity cancer in the Indian Subcontinent challenges and opportunities. Clin Oncol (R Coll Radiol). 2019;31(8):520-28. D OI: 10.1016/j.clon.2019.05.013.

3. Jitender S, Sarika G, Varada H R, O mprakash Y, M ohsin K. Screening for oral cancer. J Exp T her Oncol. 2016; 11(4):303307.

4. Chaudhry A, M anjunath M, Ashwatappa D, K rishna S, K rishna $A G$. Comparison of chemiluminescence and toluidine blue in the diagnosis of dysplasia in leukoplakia: a cross-sectional study. J Investig Clin Dent. 2016; 7(2):132-40. DOI: 10.1111/jicd.12141.

5. Jayasinghe RD, H ettiarachchi PVKS, Amugoda D, Kumaraarachchi $M$, Liyanage RLPR, Siriwardena BSM S, G unasena R, Karunatilake AHTS, Amarasinghe HK. Validity of toluidine blue test as a diagnostic tool for high risk oral potentially malignant disorders- a multicentre study in Sri Lanka. J Oral Biol Craniofac Res. 2020; 10(4):547-551. D OI: 10.1016/j.jobcr.2020.08.002. 
6. Kalmar JR. Advances in the detection and diagnosis of oral precancerous and cancerous lesions. J O ral M axillofacial Surg Clin N Am 2006; 18:465-82.

7. Sujir N, Ahmed J, Pai K, D enny C, Shenoy N. Challenges in early diagnosis of oral cancer: Cases series. Acta Stomatol Croat. 2019; 53(2):174-180. D OI: 10.15644/asc53/2/10.

8. N eville BW, Damm DD, Allen CM, Epithelial pathology In: Oral and maxillofacial pathology.3rd edition. Philadelphia: W B Saunders; 2009:362-452.

9. Cheraghlou S, Schettino A, Zogg CK, Judson BL. Changing prognosis of oral cancer: An analysis of survival and treatment between 1973 and 2014. Laryngoscope. 2018; 128(12):27622769. D OI: 10.1002/lary.27315.

10. Epstein JB, Silverman S, Epstein JD, Lonky SA, Bride MA. Analysis of oral lesion biopsies identified and evaluated by visual examination, chemiluminescence and toluidine blue. O ral Oncol 2008, 44:534-44.

11. Awadallah M, Idle M, Patel K, Kademani D. M anagement update of potentially pre-malignant oral epithelial lesions. O ral Surg O ral M ed O ral Pathol O ral Radiol. 2018;125(6):628-636. D OI: 10.1016/j.0000.2018.03.010.

12. K owalski LP, Oliveira M M , L opez RVM, Silva DRM E, Ikeda $M K$, Curado MP. Survival trends of patients with oral and oropharyngeal cancer treated at a cancer center in São Paulo, Brazil. Clinics (Sao Paulo). 2020;75:e1507. DOI: 10.6061/clinics/2020/e1507

13. Lai $K$, Killingsworth $M, M$ atthews $S, C$ aixeiro $N$, Evangelista C, W u X, W ykes J, Samakeh A, Forstner D, N iles N, H ong A, Lee CS. Differences in survival outcome between oropharyngeal and oral cavity squamous cell carcinoma in relation to H PV status. J O ral Pathol M ed. 2017;46(8):574-582. D OI: 10.1111/jop.12535.

14. D 'souza S, Addepalli V. Preventive measures in oral cancer: An overview. Biomed Pharmacother. 2018;107:72-80. DOI: 10.1016/j.biopha.2018.07.114

15. Chakraborty D, N atarajan C, M ukherjee A. Advances in oral cancer detection. Adv Clin Chem. 2019;91:181-200. DOI: 10.1016/bs.acc.2019.03.006.
16. Vijayakumar $\mathrm{V}$, Reghunathan $\mathrm{D}, \mathrm{E}$ dacheriyan $\mathrm{B}, \mathrm{M}$ ukundan $\mathrm{A}$. Role of toluidine blue staining in suspicious lesions of oral cavity and oropharynx. Indian J O tolaryngol H ead N eck Surg. 2019;71( 1):142-46. D OI: 10.1007/s12070-017-1161-y

17. Hadzic S, Gojkov-Vukelic M, Pasic E, Dervisevic A Importance of early detection of potentially malignant lesions in the prevention of oral cancer. $M$ ater Sociomed. 2017;29(2):129-133. D OI: 10.5455/msm.2017.29.129-133.

18. Singh D, Shukla RK. U tility of toluidine blue test in accessing and detecting intra-oral malignancies. Indian J Otolaryngol H ead N eck Surg. 2015;67(01):47-50. D OI: 10.1007/s12070014-0747-x

19. O nofre M A, Sposto M R, N avarro CM . Reliability of toluidine blue application in the detection of oral epithelial dysplasia and in situ and invasive squamous cell carcinomas. O ral Surg Oral M ed Oral Pathol O ral Radiol Endod. 2001;91:535-40.

20. H egde CM , K amath PN , Sreedharan S. Supravital staining: It's role in detecting early malignancies. Indian J O tolaryngol $\mathrm{H}$ ead N eck Surg. 2006;58:31-4.

21. G upta A, Singh M, Ibrahim R, M ehrotra R. U tility of toluidine blue staining and brush biopsy in pre-cancerous and cancerous oral lesions. Acta Cytol. 2007;51:788-94.

22. Algadi $\mathrm{HH}$, Abou-Bakr AA, Jamali OM, Fathy L M. T oluidine blue versus frozen section for assessment of mucosal tumor margins in oral squamous cell carcinoma. BMC Cancer. 2020;20(1):1147. D OI: 10.1186/s12885-020-07644-0.

23. Prajeesh KM, Soni S. A study of toluidine blue staining in suspected oral malignancies in patients presenting to tertiary care hospital in central India. Indian J O tolaryngol H ead $\mathrm{N}$ eck Surg. 2019;71(4):492-497. D OI: 10.1007/s12070-019-01672-4

24. Li YN, Lu R, Zhang J, Zhou G. Inter-and intra-observer agreement on the judgment of toluidine blue staining for screening of oral potentially malignant disorders and oral cancer. Clin Oral Investig. 2019;23(4):1709-1714. DOI: 10.1007/s00784-018-2595-7.

25. Parakh M K, U laganambi S, Ashifa N, Premkumar R, Jain AL. Oral potentially malignant disorders: clinical diagnosis and current screening aids: a narrative review. Eur J Cancer Prev. 2020;29(1):65-72. D OI: 10.1097/CEJ.0000000000000510 